Gilt, 1980, 21, 933940

\title{
Crohn's disease of the distal ileum
}

\author{
CLARE S HIGGENS AND R N ALLAN* \\ From the Gastroenterology Unit, The General Hospital, Birmingham
}

SUMmary A clinical and statistical analysis has been undertaken in a consecutive series of 227 patients with Crohn's disease involving the distal ileum under long-term review between 1944 and 1978. We have determined the long-term prognosis, cumulative reoperation rates after each resection, mortality rates, and their causes. Actuarial analysis has shown that the reoperation rates are similar after first, second, and third resections. There was no evidence that additional operations increase the risk of yet more resections. Reoperation rates were very little influenced by the age at diagnosis of the underlying Crohn's disease. A short interval from the diagnosis of Crohn's disease to the first resection tended to increase the reoperation rate in the short term but there was no overall long-term effect. There was a two-fold increase in mortality risk when compared with the general population. Half the deaths were unrelated to the underlying Crohn's disease and, in this group, the incidence and causes were similar to those expected in the general population matched for age, sex, and years at risk. Of the disease related deaths many occurred in the early years of experience. Only four patients in the series have died of Crohn's disease in the last 10 years. One hundred and ninety-three patients are still alive after a mean interval of 16.1 years from the diagnosis of Crohn's disease. Full information is available on 185, of whom 161 are well and symptom free. Seven have minor problems, while 17 are unwell (nine with radiological evidence of recurrent disease).

Since the definitive description of Crohn's disease ${ }^{1}$ it has become clear that the disorder may involve any part of the gastrointestinal tract.' ileum remains the most commonly involved site, and is the subject of this study. Much has been written of the symptoms, signs, complications, and response to therapy. ${ }^{3 \cdot 5}$ Many early studies of the surgical treatment and recurrence rates are difficult to interpret because no allowances were made for variations in the length of individual follow-up. There have been few studies in which the data have been analysed so that definitive conclusions can be drawn about prognosis. Lennard-Jones and his colleague $^{6}$ drew attention to the analytical problems and demonstrated the importance of using cumulative reoperation rates for effective analysis of the outcome of surgical treatment. In their series 73 patients were treated by primary resection for ileal disease of whom 12 had undergone a second resection for recurrent disease. After the first resection the cumulative reoperation rates were $16 \%$ at five years,

*Address for reprint requests: Dr R N Allan, Gastroenterology Unit, The General Hospital, Steelhouse Lane, Birmingham B4 6NH

Received for publication 4 June 1980 and $26 \%$ at 10 years. Kyle analysed a group of 62 patients undergoing primary ileal resection for Crohn's disease of whom 17 had symptomatic recurrences, and found a cumulative symptomatic recurrence rate of $20 \%$ at five years and $33 \%$ at 10 years.

The nature of the operative procedure is important because the cumulative reoperation rates tend to be higher after by-pass surgery than resection. In a recent series the recurrence rates after bypass surgery were $94 \%$ compared with $55 \%$ after resection. $^{8}$

There is conflicting evidence concerning the reoperation risk after the initial and subsequent resections. Van Patter and his colleagues ${ }^{9}$ suggested that the risk of requiring further surgery was greater after a second resection than after the initial ileal resection, while others have found that the recurrence rate was unaffected by the number of previous resections. ${ }^{10}$ Lennard-Jones and his colleagues estimated that the cumulative probability of recurrence after a second resection was nearly twice that after the first, although these estimates were based on small numbers of cases. ${ }^{6}$ It has even been suggested that, if a programme of resection is followed, the 
patient may finally be left with very little small intestine. ${ }^{11}$

Recurrence rates may be influenced by the age at which patients develop their Crohn's disease and also by the interval between the diagnosis of Crohn's disease and the initial resection. Two reports ${ }^{71:}$ suggested that recurrence rates were higher if the disease started in young adult life, while others have found that the recurrence rates are unrelated to the age at diagnosis of Crohn's disease. ${ }^{6}$ The recurrence rates may also be higher in those patients with a short interval between diagnosis and the initial resection. ${ }^{36}$

We have attempted to resolve these controversies by studying the long-term outcome among a large series of patients under long-term review with Crohn's disease in whom the macroscopic disease was confined to the distal ileum with or without minimal extension into the caecum and right colon. We have calculated the cumulative reoperation rates for recurrent disease after the initial and subsequent operations, to determine if additional surgery increases the risk of yet more resection. The rates have also been calculated in patients undergoing primary resection by excluding those patients initially treated by a bypass procedure, and in patients grouped according to age at diagnosis of their Crohn's disease and the interval between the onset of symptoms and primary resection.

\section{Methods}

PATIENTS STUDIED

Between I January 1944 and I January 1979, 520 patients with Crohn's disease have been followed at The General Hospital, Birmingham (under the care of one physician, Dr W T Cooke until January 1977 and subsequently by Dr R N Allan).

Two hundred and thirty-eight of the 520 patients $(46 \%)$ presented with Crohn's disease of the terminal ileum. Nine patients have been excluded because of incomplete follow-up data, so that 227 were available for study. Of the $227,77(34 \%)$ had extension of the disease into the caecum, or immediately adjacent proximal colon, but there was no macroscopic or radiological evidence of disease elsewhere. The case records of all these patients have been reviewed and the relevant information extracted for analysis. One hundred and ninety-three patients are still alive (114 female, 79 male) and 34 have died ( 13 female and 21 male). The mean age at the onset of symptoms among the 227 patients was 30.9 years (SD 14.4 years) and at the diagnosis of Crohn's disease 33.3 years ( $\mathrm{SD} 14.6$ years). The mean interval from the onset of symptoms to diagnosis was $2 \cdot 4$ years. The disorder is predominantly one affecting young adults, for the modal age at the onset of symptoms and at diagnosis was 20 to 24 years. The mean interval between the diagnosis of Crohn's disease and the close of this study among the patients who are still under review was 16.1 years (range 0.5 to 49 years).

DIAGNOSIS OF CROHN'S DISEASE

The diagnosis of Crohn's disease was established on clinical, radiological, and histological grounds. Surgical specimens were available for histopathological examination in 199 of the 227 patients. Of the remaining 28 , four had characteristic radiological changes in the distal ileum and subsequently had histological evidence of Crohn's disease on rectal biopsy. Twenty-four had a consistent clinical picture and typical radiological changes in the distal ileum which have been confirmed subsequently at laparotomy in nine patients. The first date at which there was either radiological or histopathological evidence of Crohn's disease has been used as the date of diagnosis.

\section{PRINCIPLES OF MANAGEMENT}

Patients have been under regular review with clinical, biochemical, and haematological assessment at least twice a year, to ensure the early detection and treatment of complications before the problems of gross malnutrition, extensive sepsis, or electrolyte imbalance have supervened. Most patients have received symptomatic relief for diarrhoea and haematinic supplements. The use of corticosteroid therapy has generally been restricted to selected patients with recurrent disease and no evidence of stricture, abscess, or fistula formation. One patient has been treated with azathioprine. None has received parenteral nutrition. Peri-operative care included the correction of anaemia, electrolyte imbalance, and steroid and antibiotic cover as required.

\section{SURGICAL TREATMENT}

Nearly all patients have undergone surgical treatment at some time during the course of their disease. The principle indications for surgery have been recurrent obstructive episodes or the presence of abscess or fistula formation. Growth retardation was the primary indication for surgery in a few patients. During the period of review all the surgery has been done by four consultant surgeons. Surgical resection has been limited to macroscopic disease in the ileum or proximal colon and bypass procedures were rarely used. The resection usually includes a few centimetres of macroscopically normal gut on either side of the involved segment. No attempt was made at wide excision in macroscopically normal 
gut and minor skip lesions remote from the main side of macroscopic disease were not resected.

CUMULATIVE RECURRENCE RATE

The cumulative recurrence rate is defined as the ratio of the number of patients experiencing a recurrence treated by resection during each year of follow-up to the number of patients who were at risk during that year.

Unlike the crude recurrence rates, this method corrects for varying length of follow-up in the individual patients. The actuarial methods of analysis for this study have been summarised by Greenstein and his colleagues ${ }^{13}$ and are based on methods developed by Berkson and Gage. ${ }^{14}$ The cumulative recurrence rates, which are based in this study on resections for histologically proven recurrent disease, will be somewhat lower than the recurrence rates calculated on radiological evidence of recurrent disease alone.

A bypass operation was the primary procedure in 19 patients and a secondary procedure in one, though resection of the bypassed segment was commonly required soon afterwards. Such patients are usually included for calculating cumulative reoperation rates as if they had recurrent disease. We have adopted this approach to allow for effective inter-series comparisons.

\section{Results}

\section{MEDICAL TREATMENT}

Sixty-five patients have been treated with corticosteroids at some time during the course of their illness, of whom 31 have received treatment for more than six months. One patient was receiving

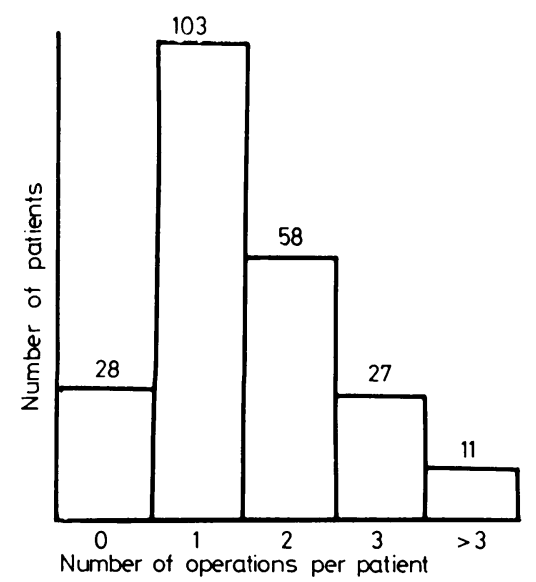

Fig. 1 Number of operations (resections and bypasses) for Crohn's disease of the distal ileum.
Table 1 Sites of recurrent macroscopic disease resected $(n=79)$ after initial resections of distal ileum $(n=180)$

\begin{tabular}{ll}
\hline Site & (no.) \\
\cline { 1 - 1 } Ileum at or immediately proximal & \\
to anastomosis & 57 \\
Proximal to anastomosis & 15 \\
Distal to anastomosis & 7 \\
\hline
\end{tabular}

azathioprine when first seen here. None has received parenteral nutrition.

SURGICAL TREATMENT

One hundred and ninety-nine of the 227 patients $(87.6 \%)$ have been treated surgically during the course of their disease.

Despite the long period of review the majority of patients $(52 \%)$ have required only a single resection. Less than $6 \%$ have had more than three resections. A total of 327 resections and 20 bypasses have been performed. All but one of the bypass procedures were carried out as the primary operation (Fig. 1). Recurrent disease was nearly always localised to the ileum immediately at or proximal to the previous anastomosis, though seven patients have developed extensive colonic involvement requiring colectomy (Table 1). Twenty-eight patients have not needed any surgical treatment.

Table 2 Cumulative recurrence rates after initial and subsequent operations for Crohn's disease of the distal ileum

\begin{tabular}{|c|c|c|c|c|}
\hline \multirow{2}{*}{$\begin{array}{l}\text { Year of } \\
\text { follow'-llp) }\end{array}$} & \multicolumn{2}{|l|}{ Resection } & \multirow[b]{2}{*}{$\begin{array}{l}\text { After } 2 \text { nd } \\
\left({ }^{0}, 0\right)\end{array}$} & \multirow[b]{2}{*}{$\begin{array}{l}\text { After ird } \\
\left(\begin{array}{c}0 \\
0\end{array}\right)\end{array}$} \\
\hline & $\begin{array}{l}\text { After first } \\
(0)\end{array}$ & $\begin{array}{l}\text { After first } \\
\text { or bypass } \\
\text { procedlure } \\
(\%)\end{array}$ & & \\
\hline $0-1$ & $5 \cdot 6$ & $8 \cdot 6$ & $2 \cdot 1$ & $2 \cdot 4$ \\
\hline 1-2 & $7 \cdot 4$ & 11.0 & $5 \cdot 5$ & $5 \cdot 2$ \\
\hline $2-3$ & $11 \cdot 0$ & $14 \cdot 3$ & $10 \cdot 3$ & $11 \cdot 2$ \\
\hline $3-4$ & $14 \cdot 2$ & $17 \cdot 2$ & 14.0 & 17.8 \\
\hline $4-5$ & $17 \cdot 6$ & $20 \cdot 3$ & $20 \cdot 2$ & $32 \cdot 1$ \\
\hline $5-6$ & $20 \cdot 0$ & $24 \cdot 8$ & 25.6 & $32 \cdot 1$ \\
\hline 6.7 & $26 \cdot 3$ & $28 \cdot 7$ & $33 \cdot 8$ & 35.9 \\
\hline $7-8$ & $28 \cdot 4$ & $30 \cdot 6$ & $39 \cdot 6$ & $40 \cdot 2$ \\
\hline $8-9$ & $34 \cdot 0$ & $36 \cdot 0$ & $41 \cdot 1$ & $40 \cdot 2$ \\
\hline $9-10$ & 36.0 & $37 \cdot 7$ & $46 \cdot 0$ & $*$ \\
\hline $10-11$ & $39 \cdot 0$ & $40 \cdot 1$ & $47 \cdot 8$ & $*$ \\
\hline $11-12$ & $46 \cdot 0$ & $47 \cdot 8$ & $49 \cdot 7$ & $*$ \\
\hline $12-13$ & $47 \cdot()$ & $48 \cdot 7$ & $51 \cdot 6$ & $*$ \\
\hline $13-14$ & $49 \cdot 0$ & 50.4 & $55 \cdot 5$ & $*$ \\
\hline $14-15$ & $51 \cdot 0$ & $51 \cdot 0$ & $*$ & $*$ \\
\hline $15-16$ & 53.0 & $51 \cdot 4$ & $*$ & $*$ \\
\hline $16-17$ & 54.0 & $54 \cdot 3$ & $*$ & $*$ \\
\hline $17-18$ & $55 \cdot 0$ & $55 \cdot 4$ & * $\cdot$ & $*$ \\
\hline $18-19$ & $55 \cdot 0$ & $55 \cdot 4$ & * & $*$ \\
\hline $19-20$ & 55.0 & 55.4 & $*$ & $*$ \\
\hline $\begin{array}{l}\text { No. of } \\
\text { patients }\end{array}$ & & & & \\
\hline $\begin{array}{l}\text { followed } \\
\text { at last } \\
\text { estimate }\end{array}$ & 27 & 44 & 20 & 8 \\
\hline
\end{tabular}

* Number too small for effective interpretation. 


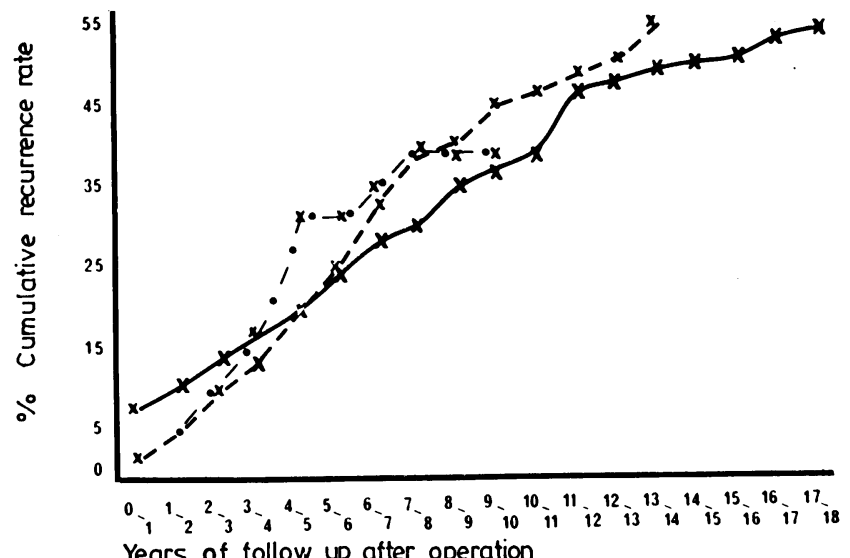

Fig. 2 The cumulative recurrence rates after the initial resection or bypass procedure (-) and after second (- ) and third (-*-) resections. (Subscript: number of operations/ number of patients under review in each year of follow-up).

$\begin{array}{lllllllllllllllllll}\text { After first } & \frac{17}{199} & \frac{4}{161} & \frac{6}{155} & \frac{5}{147} & \frac{5}{135} & \frac{7}{124} & \frac{6}{115} & \frac{3}{109} & \frac{7}{98} & \frac{3}{86} & \frac{3}{77} & \frac{9}{69} & \frac{1}{60} & \frac{2}{57} & \frac{1}{50} & \frac{2}{49} & \frac{1}{44} & \frac{1}{45}\end{array}$ and bypass

After 2nd

$\begin{array}{lllllllllllllll}\frac{2}{96} & \frac{3}{86} & \frac{4}{79} & \frac{3}{74} & \frac{5}{69} & \frac{4}{60} & \frac{6}{54} & \frac{4}{46} & \frac{1}{38} & \frac{3}{36} & \frac{1}{31} & \frac{1}{27} & \frac{1}{26} & \frac{2}{25}\end{array}$

After 3rd $\quad \frac{1}{41} \quad \frac{1}{34} \quad \frac{2}{32} \quad \frac{2}{27} \quad \frac{4}{23} \quad \frac{0}{18} \quad \frac{1}{16} \quad \frac{1}{15} \quad \frac{0}{13} \quad \frac{0}{12} \quad \frac{0}{10}$

\section{CUMULATIVE RECURRENCE RATES}

\section{All surgical procedures}

The cumulative recurrence rates after the first, second, and third resections for histologically proven recurrent disease have been calculated to determine how the number of resections influences the recurrence rates (Table 2 ). The rates after the first operation have been calculated for the whole group and for those patients undergoing primary resection excluding bypass procedures. Because all but one of the bypasses were carried out as a primary procedure no correction was required for the recurrence rates after the second and third resections.

The cumulative recurrence rates for each year of follow-up after the first, second, and third operations were similar, except that there was a higher recurrence rate in the first two years after the initial operation than was observed in the same period after the second and third resections (Fig. 2).

This difference is partly, but not entirely, due to

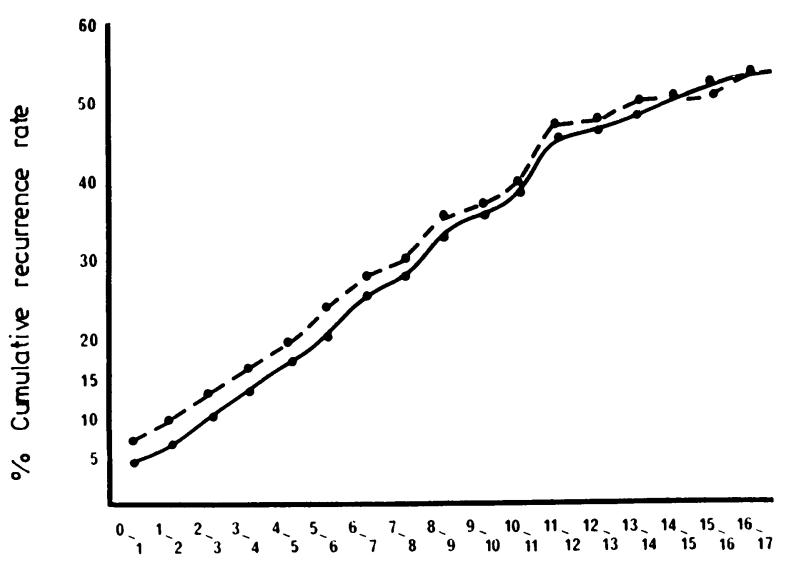

Years of follow up

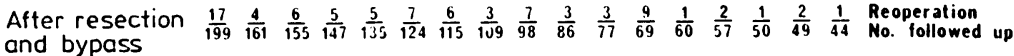

$\begin{array}{llllllllllllllllll}\text { After resection } & \frac{10}{180} & \frac{3}{154} & \frac{5}{145} & \frac{4}{138} & \frac{5}{127} & \frac{6}{118} & \frac{6}{108} & \frac{3}{102} & \frac{7}{91} & \frac{3}{79} & \frac{3}{70} & \frac{8}{62} & \frac{1}{54} & \frac{2}{51} & \frac{1}{44} & \frac{2}{43} & \frac{1}{39} \begin{array}{l}\text { Reoperation } \\ \text { Only }\end{array}\end{array}$ only

Fig. 3 A comparison of the cumulative reoperation rates after the first operation (resection and bypass procedures) (- -) and resection alone (-). 


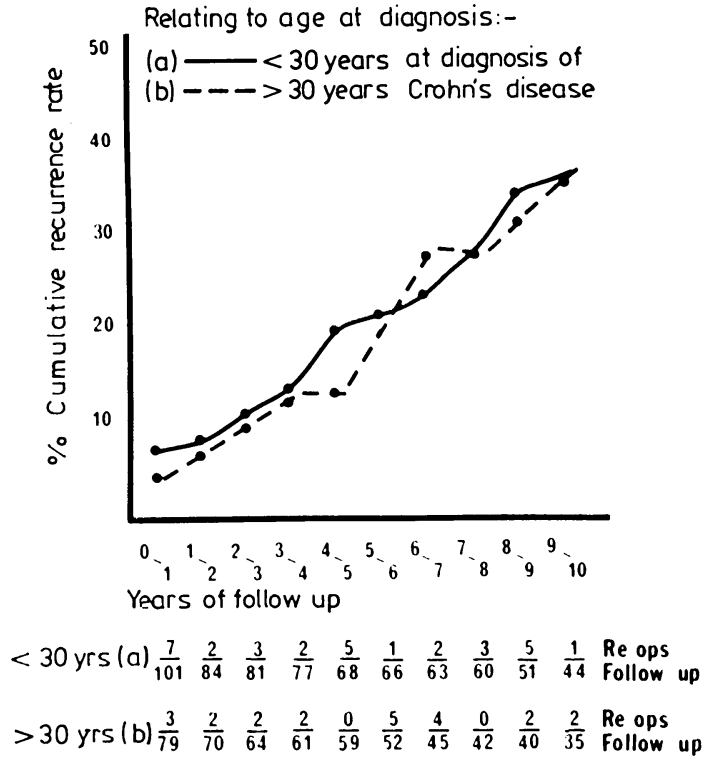

Fig. 4 Cumulative recurrence rates after the initial resection related to the age at diagnosis of the underlying Crohn's disease.

those patients treated initially by a bypass procedure with early resection of the bypassed segment for persistent symptoms (Fig. 3).

RESECTION ALONE

Recurrence rates vs age at onset of Crohn's disease

The cumulative recurrence rates after the first resection have been calculated according to the age at diagnosis of their Crohn's disease (Fig. 4). There was little difference between the recurrence rates in the two groups who were diagnosed as having Crohn's disease before and after 30 years of age.

Recurrence rates vs duration of symptoms before first resection

The cumulative recurrence rates after the first resection have been plotted for the two groups of patients who underwent their first resection either more than or less than 2.5 years since the onset of symptoms (Fig. 5). The results suggest that the recurrence rates are higher with a shorter symptomatic interval before the first resection.

\section{MORTALITY RATES}

Thirty-four of the 227 patients have died $(15 \%)$. The mean age at death was 55.4 years (range 18 to 88 years) with a mean interval from diagnosis of Crohn's disease to death of 14.9 years (range 0.5 to 39 years). The principal causes of unrelated deaths were carcinoma (excluding the digestive tract)

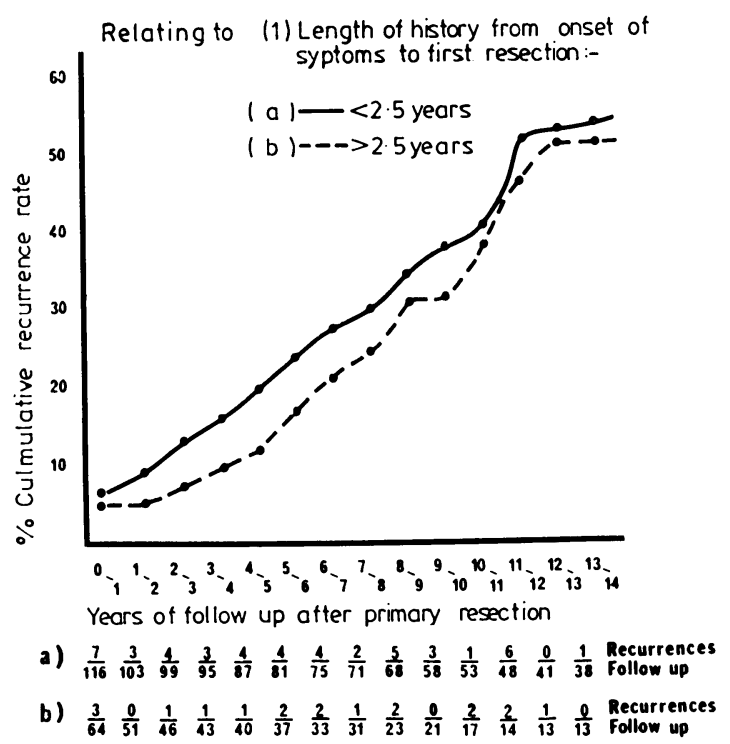

Fig 5 Cumulative recurrence rates after the initial resection (not bypasses) for Crohn's disease of the distal ileum related to the interval between the onset of symptoms of Crohn's disease and the first resection.

(seven), cerebrovascular disease (three), ischaemic heart disease (three), cor pulmonale (one), suicide (one), and unknown (three).

Sixteen of the 34 deaths were attributed to Crohn's disease and are summarised in Table 3. Of the 16 deaths, four were probably unavoidable (amyloidosis (two) and steroid induced hypertension and renal failure (two)). Most of the remaining 12 deaths occurred between 1944-66 (Fig. 6), principally from sepsis or severe electrolyte imbalance and included two patients who were moribund on admission. Recent advances in clinical management, particularly antibiotic therapy, should minimise such problems in the future. Only four patients in this series have died from complication of their Crohn's disease in the past 10 years.

\section{CURRENT STATUS}

One hundred and ninety-three of the 227 patients are still alive. One hundred and eighty-five $(95.8 \%)$ were seen during 1978. Their current clinical status has been assessed and haematological and biochemical indices of disease activity measured (haemoglobin, serum albumin, and serum orosomucoids). Additional radiological assessment has been carried out in symptomatic patients. One hundred and sixtyone of the 185 patients are fit, well, and leading reasonably normal lives. Seven have persistent symptoms (perianal disease, two; diarrhoea, five) 


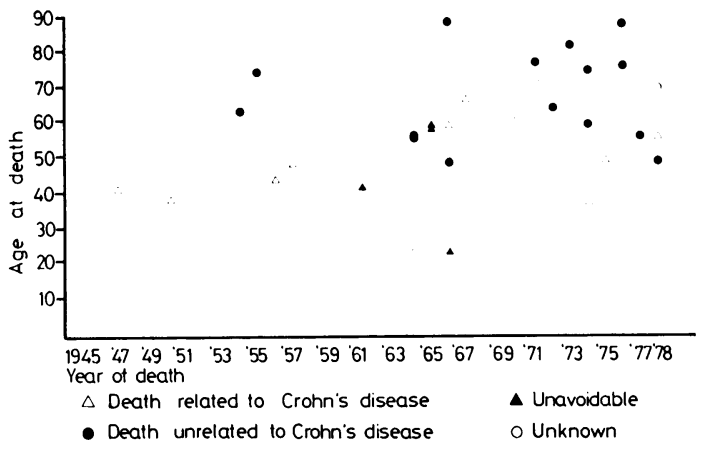

Fig. 6 Deaths among patients with Crohn's disease of the distal ileum 1944-78.

and 17 are unwell (nine with radiological evidence of recurrent disease).

One hundred and eighteen of the $185(63.8 \%)$ have normal indices (haemoglobin $13 \mathrm{~g} / \mathrm{dl}$, serum albumin $40 \mathrm{~g} / \mathrm{l}$, serum orosomucoids $1.5 \mathrm{~g} / \mathrm{l}(150$ $\mathrm{mg} \%$ ).

\section{RECURRENT DISEASE}

Based on the radiological examinations of the small intestine between 1972 to 1978,26 patients $(14 \%)$ have radiological evidence of recurrent disease without requiring further resection. Nine are symptomatic and 17 are symptom free.

As a guide to the prevalence of surgical treatment 11 of the 193 patients in this series had resections during 1978.

\section{CURRENT THERAPY}

Few of the 185 patients are currently receiving 'specific' therapy such as corticosteroids, though the majority require non-specific haematinic therapy, or anti-diarrhoeal agents for symptomatic relief (Table 4).

\section{Discussion}

Crohn's disease may involve any part of the gastrointestinal tract but the distal ileum remains the most commonly affected site, so that the management and long-term prognosis of this group of patients are of particular interest and importance.

Until the aetiology of Crohn's disease is established these results demonstrate that a policy of surgical resection in experienced hands for persistent symptoms in the presence of obstructive episodes, abscess, or fistula formation can produce good longterm results in most patients. We agree with de Dombal ${ }^{10}$ that reoperation rates for recurrent disease are little affected by the number of previous resections. The recurrence rates are principally a function of the length of follow-up. ${ }^{13}$ Although the recurrence rates in individual years tend to be higher after the second rather than the initial resection (Table 2) as described by others ${ }^{6}{ }^{9}$ the overall pattern in the two groups is similar (Fig. 2).

A few patients developed early recurrence within two years of their primary operation. It is particularly common after an initial bypass procedure. However, the cumulative recurrence rates revert to the normal pattern even in those patients who after an initial resection require early reoperation for recurrent disease. These findings provide effective reassurance for both the patient and the physician unnecessarily dismayed by an early recurrence. A second resection if symptoms persist does not preclude a good long-term outcome. We agree with Lennard-Jones ${ }^{6}$ that the age at diagnosis of Crohn's

Table 3 Deaths related to Crohn's disease

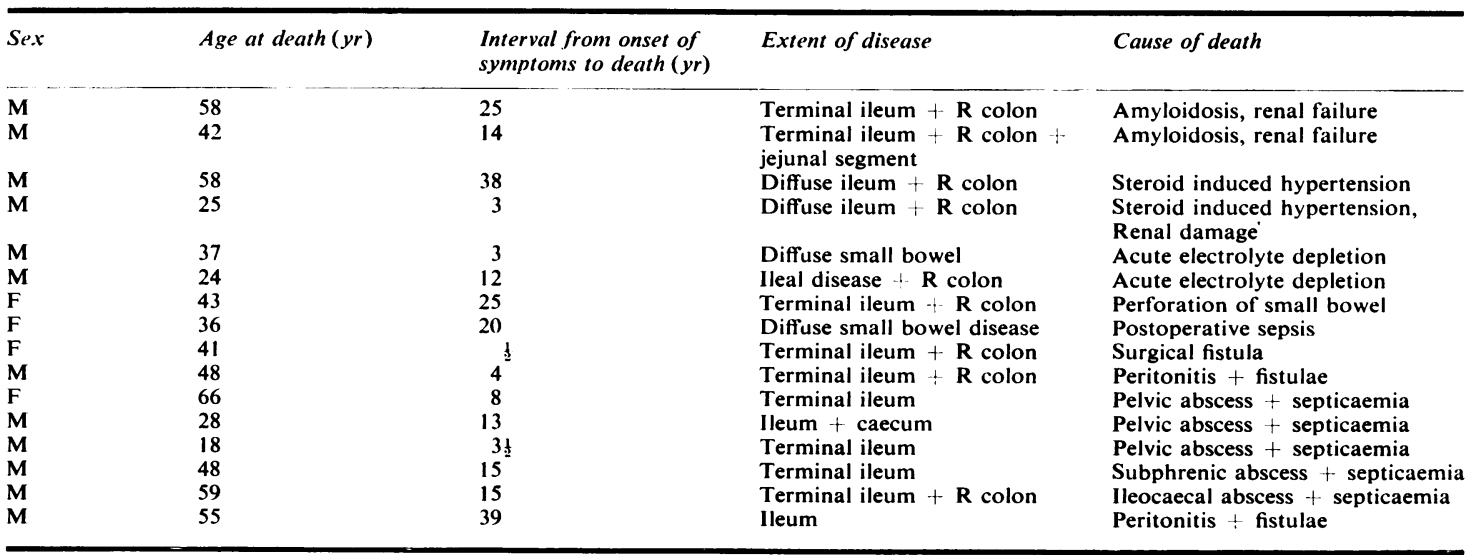


Table 4 Present treatment in 185 patients still under review

\begin{tabular}{lc}
\hline Therapy & $($ no. $)$ \\
\hline Specific & \\
Prednisone & 5 \\
ACTH & 5 \\
Sulphasalazine & 9 \\
Sulphasalazine + ACTH & 1 \\
Non-specific & \\
Antidiarrhoeal drugs & 32 \\
Cholestyramine & $\mathbf{8}$ \\
Folate + B12 + iron & $\mathbf{8 8}$ \\
\hline
\end{tabular}

disease does not influence the recurrence rate as has been suggested. ${ }^{73}$

Because recurrence rates are a function of time we would support the principle advocated by $\mathrm{Kiefer}^{15}$ that patients with Crohn's disease should be under regular medical supervision so that they receive informed, consistent advice, and early detection and treatment of complications.

After an initial resection (other than a bypass procedure) for Crohn's disease of the terminal ileum, patients have an even chance of needing a second resection within 15 years. The average patient having a first resection at the age of 25 years is likely to need two or three more resections, usually for recurrence at the anastomosis during their lifetime.

Our recurrence rates (based on resections for recurrent disease) are rather higher than in other reported series ${ }^{6}{ }^{7}$ suggesting that surgical treatment may have been advised for less severe and persistent symptoms. However, the surgical bias in our approach to management seems to have been very successful. It is important to emphasise that recurrent disease is usually confined to a local recurrence at the anastomosis, which is readily treated with minimum morbidity and mortality.

Younger patients ${ }^{16}$ and those with a short pre- resection history ${ }^{17}$ may have a higher than average recurrence rate. Our data suggest a higher cumulative recurrence rate only in those patients in whom there was a short interval between diagnosis of their Crohn's disease and primary resection (less than 2.5 years). However the differences are small and do not affect the good long-term prognosis.

There may be other factors which affect recurrence rates, though Gump and his colleagues ${ }^{24}$ found that the length of normal bowel resected above the macroscopic disease did not affect the outcome, while Van Patter and his colleagues ${ }^{9}$ could find no difference in recurrence rates between patients with and without histological evidence of granuloma formation.

The crude mortality rate of $7 \%$ related to Crohn's disease is similar to the rates reported by others (Table 5). More than half the patients have died of unrelated causes. The observed, unrelated deaths are similar to those expected in a group of patients drawn from the general population and matched for age, sex, and years at risk. Despite the long period of review, only 16 of the deaths were related to the underlying Crohn's disease and four of them were probably unavoidable. Many of the others occurred in the early years, usually from overwhelming sepsis or electrolyte imbalance. These problems are now much less common. During the last 10 years only four patients in this series have died from complications of their disease.

Regular review and a surgical policy of resection for recurrent obstructive symptoms and abscess or fistula formation should ensure a good long-term prognosis. The majority of patients remain well many years after the diagnosis of Crohn's disease. This good long-term prognosis conforms with the view of others. ${ }^{1315}$ The few patients requiring inpatient treatment of complications at any one time tend to exaggerate the problem of the majority who mostly attend hospital only once or twice a year and otherwise live a relatively normal social life.

Table 5 Mortality rates from Crohn's disease

\begin{tabular}{|c|c|c|c|c|c|c|}
\hline \multirow[t]{2}{*}{ Authors } & \multirow{2}{*}{$\begin{array}{l}\text { Period of } \\
\text { observation }\end{array}$} & \multirow[t]{2}{*}{ Patients (no.) } & \multirow[t]{2}{*}{ Deaths (no.) } & \multirow[t]{2}{*}{ Total mortality } & \multicolumn{2}{|c|}{ Deaths due to Crohn's disease } \\
\hline & & & & & (no.) & $(\%)$ \\
\hline $\begin{array}{l}\text { Davis }(1961)^{18} \\
\text { Banks et al. }(1969)^{19} \\
\text { Edwards }(1963)^{20} \\
\text { Prior et al. }(1970)^{21} \\
\text { Krause et al. }(1971)^{22} \\
\text { Verschuyl }(1971)^{23} \\
\text { de Dombal et al. }(1971)^{10} \\
\text { Kyle }(1972)^{11} \\
\text { Truelove }(1976)^{4} \\
\text { Present series }\end{array}$ & $\begin{array}{l}1949-58 \\
1929-63 \\
1936-66 \\
1931-68 \\
1956-68 \\
1930-66 \\
1939-68 \\
1955-69 \\
1938-71 \\
1944-78\end{array}$ & $\begin{array}{l}141 \\
168 \\
279 \\
295 \\
186 \\
138 \\
295 \\
166 \\
221 \\
227\end{array}$ & $\begin{array}{l}16 \\
25 \\
53 \\
13 \\
27 \\
54 \\
17 \\
32 \\
34\end{array}$ & $\begin{array}{r}11 \cdot 3 \\
14 \cdot 8 \\
17 \cdot 2 \\
18 \cdot 0 \\
7 \cdot 0 \\
19 \cdot 5 \\
18 \cdot 3 \\
10 \cdot 2 \\
14 \cdot 3 \\
14 \cdot 9\end{array}$ & $\begin{array}{l}13 \\
16 \\
-33 \\
10 \\
18 \\
41 \\
12 \\
17 \\
16\end{array}$ & $\begin{array}{r}9 \cdot 8 \\
9 \cdot 5 \\
11 \cdot 2 \\
5 \cdot 4 \\
13 \cdot 0 \\
13 \cdot 9 \\
7 \cdot 2 \\
7 \cdot 7 \\
7 \cdot 0\end{array}$ \\
\hline
\end{tabular}

Adapted from Truelove and Pena (1976)4 


\section{References}

${ }^{1}$ Crohn BB, Ginzburg L, Oppenheimer GD. Regional ileitis: a pathologic and clinical entity. JAMA 1932; 99: 1323-9.

${ }^{2}$ Farmer RG, Hawk WA, Turnbull RB Jr. Clinical patterns in Crohn's disease: a statistical study of 615 cases. Gastroenterology 1975; 68: 627-35.

${ }^{3}$ de Dombal FT, Burton IL, Clamp SE, Goligher JC. Short-term course and prognosis of Crohn's disease. Gut 1974; 15: 435-43.

${ }^{4}$ Truelove SC, Peña AS. Course and prognosis of Crohn's disease. Gut 1976; 17: 192-201.

${ }^{5}$ Bergman L, Krause U. Crohn's disease, a long-term study of the clinical course in 186 patients. Scand $J$ Gastroenterol 1977; 12: 937-44.

${ }^{6}$ Lennard-Jones JE, Stalder GA. Prognosis after resection of chronic regional ileitis. Gut 1967; 8: 332-6.

'Kyle J. Prognosis after ileal resection for Crohn's disease. Br J Surg 1971; 58: 735-7.

${ }^{8}$ Homan WP, Dineen P. Comparisons of the results of resection, bypass, and bypass with exclusion for ileocecal Crohn's disease. Ann Surg 1978; 187: 530-5.

${ }^{\circ}$ Van Patter WN, Bargen JA, Dockerty MB, Feldman WH, Mayo CW, Waugh JM. Regional enteritis. Gastroenterology 1954; 26: 347-450.

${ }^{10}$ de Dombal FT, Burton IL, Goligher JC. Recurrence of Crohn's disease after primary excisional surgery. Gut 1971; 12: 519-27.

${ }^{11}$ Kyle J. Crohn's disease. London: Heinemann, 1972: 195.

${ }^{12}$ Stahlgren LH, Ferguson LK. The results of surgical treatment of chronic regional enteritis. JAMA 1961; 175: 986-9.
${ }^{13}$ Greenstein AJ, Sachar DB, Pasternack BS, Janowitz HD. Re-operation and recurrence in Crohn's colitis and ileocolitis. N Engl J Med 1975; 293: 685-90.

${ }^{14}$ Berkson J, Gage RP. Calculation of survival rates for cancer. Proc Staff Mtg Mayo Clinic 1950; 25: 270-86.

${ }^{15}$ Kiefer ED, Marshall SF, Brolsma MP. The management of chronic regional ileitis. Gastroenterology 1950; 14: $118-30$.

${ }^{16}$ de Dombal FT. Results of surgery for Crohn's disease. Clin Gastroenterology 1972; 1: 493-506.

${ }^{17}$ Goligher JC, de Dombal FT, Burton IL. Surgical treatment and its results, regional enteritis (Crohn's disease). (Skandia International Symposium 5th) Ed Engel A, Larsson T. Stockholm: Nordiska, Bokhandelns Förlag, 1971 ; 166-76.

${ }^{18}$ Davis JM. The prognosis of Crohn's disease of the small intestine. Postgrad Med J. 1961 ; 37: 783-91.

${ }^{19}$ Banks BM, Zetzel L, Richter HS. Morbidity and mortality in regional enteritis. Report of 168 cases. Am J Dig Dis 1969; 14: 369-79.

${ }^{20}$ Edwards FC, Truelove SC. The course and prognosis of ulcerative colitis. Part II: Long term prognosis. Gut $1963 ; 4$ : 309-15.

${ }^{21}$ Prior P, Fielding JF, Waterhouse JA, Cooke WT. Mortality in Crohn's disease. Lancet 1970; 1: 1135-7.

${ }^{22}$ Krause U, Bergman L, Nórlen BJ. Crohn's disease: a clinical study based on 186 patients. Scand J Gastroenterol 1971 : 6: 97-108.

${ }^{23}$ Verschuyl MA, DeZiekte van Crohn Enteritis Regionalis Thesis. Utrecht. 1971.

${ }^{24}$ Gump FE, Sakellariadis P, Wolff M, Broell JR. ClinicalPathological investigation of regional enteritis as a guide to prognosis. Ann Surg 1972; 176: 233-42. 